\title{
Optimal Location and Capacity Planning for Distributed Generation with Independent Power Production and Self-Generation
}

\author{
Lesiba Mokgonyana ${ }^{\mathrm{a}}$, Jiangfeng Zhang ${ }^{\mathrm{b}, *}$, Hailong $\mathrm{Li}^{\mathrm{c}}$, Yihua $\mathrm{Hu}^{\mathrm{d}}$ \\ ${ }^{a}$ Department of Electronic and Electrical Engineering, University of Strathclyde, UK \\ ${ }^{b}$ School of Electrical, Mechanical and Mechatronic Systems, University of Technology Sydney, \\ Australia \\ ${ }^{c}$ School of Business, Society and Engineering, Mälardalen University, Sweden \\ ${ }^{d}$ Department of Electrical Engineering and Electronics, University of Liverpool, UK
}

Abstract

This paper proposes a planning model for power distribution companies (DISCOs) to maximize profit. The model determines optimal network location and capacity for renewable energy source, which are categorized as independent power production (IPP) and self-generation (SG). IPP refers to generators owned by third-party investors and linked to a quota obligation mechanism. SG encompasses smaller generators, supported by feed-in tariffs, that produce energy for local consumption, exporting any surplus generation to the distribution network. The obtained optimal planning model is able to evaluate network capacity to maximize profit when the DISCO is obliged to provide network access to SG and IPP. Distinct parts of the objective function, owing to the definition of SG, are revenue erosion, recovery as well as the cost of excess energy. Together with the quota mechanism for IPP, the combination of all profit components creates a connection trade-off between IPP and SG for networks with limited capacity. The effectiveness of the model is tested on 33- and 69-bus test distribution systems and compared to standard models that maximize generation capacity with predefined capacity diffusion. Simulation results demonstrate the model outperforms the standard models in satisfying the following binding constraints: minimum IPP capacity and SG net energy. It is further revealed that integrating SG and IPP with the proposed model increases profit by up to $23.7 \%$, adding an improvement of $8 \%$ over a feasible standard 
model.

Keywords: Distribution company; distributed generation; distribution network; profit maximisation; quota obligation.

\section{Introduction}

Policy makers around the world are implementing measures to accelerate the connection of renewable energy sources (RESs) in order to meet low carbon or sustainability objectives. As such, the number of countries that have some form of target setting for utilizing renewable energy has reached 164 as of 2015 [1]. Furthermore, 59 jurisdictions have targets that are legally binding. However, with increasing commitment comes concerns over the promotion of RESs. For example, distribution companies (DISCOs) risk losing profits while customers bear the cost of the related support schemes. Therefore, cost effective planning considering the locations and capacities of renewable distributed generation (DG) connections is necessary to deal with these key challenges.

There are plenty of studies on the grid connection of new DG. Approaches described in [2 6], determine locations and sizes of DG units to optimize savings arising from deferral of network upgrades, losses, reliability, and other technical objectives. It is found in [7] and [8] that there are additional financial benefits of DG connection in the form of use-of-system charges, capacity and loss reduction incentives overseen by regulators.

DG planning is carried out in diverse contexts [9 14]. In [9] the profit of a DISCO is maximized by strategic sizing and placement of third-party DG while maintaining project viability. This approach is in line with many instances whereby the DISCO coordinates generation by other producers [15], [16]. The models proposed in [10] and [11] minimize the cost of power purchased from generation companies (GENCOs), capital and operating costs of DG units owned by the DISCO, and the costs of network operation and unserved power. In [12], the objective is to maximize social welfare among DISCOs and GENCOs, and to maximize profit for the DG owner. The interaction between a DG owner and DISCO can also be treated as a bi-level problem whereby 
the DG owners profits are maximized first, followed second by the DISCOs cost of energy [13]. The work presented in [14] models the role of a central planning authority aiming to encourage GENCOs and local DISCOs achieve predefined targets for RESs. The resulting incentives ensure viability of a mix of various technology investments.

While the benefits of DG in distribution systems have been widely studied, there is a lack of focus on the implications of renewable energy policies from the DISCO's perspective concerning independent DG units. The formulation in [17] considers capacity expansion planning in the presence of renewable portfolio standards and carbon tax mechanisms. Another study investigates the impact of the aforementioned mechanisms plus feed-in tariffs (FiTs) and emission trading on expansion planning [18]. Although these models take environmental policies into account, they are solved from the perspective of a GENCO. The impact of FiTs, carbon tax and cap-and-trade mechanisms on DG investments by DISCOs and independent investors is studied in [19], with the objective being to maximize the profit from the sale of energy.

In practical settings, DG is categorized as independent power production (IPP) or self-generation (SG) [16]. IPP accounts for relatively large DG units that solely produce electricity, whereas SG represents existing customers seeking to invest in DG, with some energy being consumed on-site. IPP is promoted through a quota obligation scheme [20, 21]. The scheme requires that DISCOs supply a portion of their total load with RESs or make an alternative payment to a regulatory body. SG is typically supported by FiT incentive schemes. These schemes offer investors certainty through purchase of power at fixed rates and guaranteed payments over long periods [20, 22]. The import and export variability of SG causes changes in revenue from energy sales, whereby revenue erosion is mitigated in several ways including revenue decoupling and lost revenue adjustment mechanisms 23 26]. That means DISCOs recoup the revenue lost due to SG integration from ratepayers. Hence, by promoting DG capacity and locations that maximize profit, the cost carried by ratepayers will be reduced. Under these circumstances, there are financial implications regarding any action the DISCO takes with respect to renewable DG integration. It is therefore crucial to distinguish 
between IPP and SG.

None of the referenced studies prescribes a model that considers binding RES quotas, the combined network impact of IPP and SG, and the cost and revenue implications for the DISCO in the context of DG location and capacity planning. Therefore, this paper incorporates both IPP and SG to develop an optimization model through which the DISCO enables network access for third-party DG, and responds strategically to renewable energy policy. Given RES quota, network and DG-specific constraints, the model presented herein determines locations and capacities that are allocated to SG and IPP such that the profit of the DISCO is maximized. Distinctly, the objective function encompasses a financial penalty for non-compliance, which varies mainly with IPP deployment, revenue erosion, a cost recovery mechanism for the lost revenue, and cost of energy exported from SG locations. The proposed model is validated on 33- and 69-bus test distribution systems, and compared to standard approaches for maximizing overall DG capacity. Simulation results show there is a trade-off between SG and IPP integration, and that the proposed model provides advantages over standard approaches in terms of profit maximization and DG constraint satisfaction. In fact, the DISCO will achieve an increase of $23.7 \%$ in profits in the presence of constrained SG (net energy) and IPP (minimum capacity). This is an improvement of $8 \%$ over the standard approaches. Furthermore, the impact of each of the following parameters is analysed: renewable energy quota, SG net energy limit, revenue recovery rate, energy export rate, and minimum IPP capacity.

The next section provides a description and mathematical model of a DISCO interested in profit maximisation in an policy environment promoting RESs integration. Section 3 describes case studies involving 33-bus and 69-bus test distribution systems. Results and analyses are presented in Section 4. Section 5 presents conclusions that are drawn from the study. 


\section{DG Location and Capacity Planning Optimisation Model}

119

This section presents an optimisation model for DG location and capacity planning in terms of IPP and SG.

\subsection{Notation}

The notation defined below is employed for parameters and variables in the optimisation model.

Sets and Indices

$d, j$ Bus indices

$D \quad$ Set consisting of all buses in the system

I Set consisting of all candidate IPP buses in the system

i Candidate IPP bus index

$k \quad$ Candidate $\mathrm{SG}$ bus index

$K \quad$ Set consisting of all candidate SG buses in the system

$t \quad$ Time interval index

$\tau \quad$ Sampling interval of one hour

$T$ Set consisting of all time intervals over the evaluation period

\section{Parameters}

$C^{\text {e }}$ Wholesale price of electricity (£/MWh)

$C^{\mathrm{r}} \quad$ Retail price of electricity $(£ / \mathrm{MWh})$

$r^{\circ}$ Independent power production quota to be met by DISCO $(\%)$ 
$C^{\mathrm{b}} \quad$ Penalty rate for obligation non-compliance (£/MWh)

$C^{\text {rv }} \quad$ Revenue recovery rate $(£ / \mathrm{MWh})$

$C^{\text {ee }} \quad$ DISCO energy export rate $(£ / M W h)$

$a_{L} \quad$ Total allowed energy generation percentage for SG (\%)

$G_{\mathrm{SG}, k}^{\max } \quad$ Maximum allowable capacity for self-generation

$G_{\mathrm{IPP}, i}^{\max }$ Maximum allowable capacity for independent power production

$G_{\mathrm{IPP}, i}^{\min }$ Minimum allowable capacity for independent power production

$S_{d, j}^{\max } \quad$ Apparent power limit of component between bus $d$ and bus $j$

$P_{\mathrm{SGL}, k}^{t}$ Active power demand associated with $k$ th $\mathrm{SG}$ and $t$ th time interval (MW)

$P_{\mathrm{L}, d}^{t} \quad$ Active power demand at $d$ th bus and th time interval (MW)

$Q_{\mathrm{L}, d}^{t} \quad$ Reactive power demand at $d$ th bus and $t$ th time interval (MVAr)

$G_{d j}^{t} \quad$ Real part of admittance element between bus $d$ and bus $j$ (mho)

$B_{d j}^{t} \quad$ Imaginary part of admittance element between bus $d$ and bus $j$ (mho)

\section{Variables}

$G_{\mathrm{IPP}, i}$ Generation capacity of the $i$ th IPP

$G_{\mathrm{SG}, k} \quad$ Generation capacity of the $k$ th SG

$P_{\mathrm{IPP}, i}^{t} \quad$ Independent power production at $i$ th candidate bus and $t$ th time interval (MW)

$P_{\mathrm{SG}, k}^{t} \quad \mathrm{SG}$ power at $k$ th candidate bus and $t$ th time interval (MW)

$P_{\mathrm{s}}^{t} \quad$ Total active power delivered from substation (MW)

$P_{\mathrm{G}, d}^{t} \quad$ Active power supply at $d$ th bus and $t$ th time interval (MW)

$Q_{\mathrm{G}, d}^{t} \quad$ Reactive power supply at $d$ th bus and $t$ th time interval (MVAr)

$V_{d}^{t}, V_{j}^{t} \quad$ Bus voltages magnitude at $t$ th time interval $(\mathrm{kV})$

$\delta_{d}^{t}, \delta_{j}^{t} \quad$ Bus voltage angles at $t$ th time interval

The following sign function is defined to simplify the expression of connection and compliance statuses:

$$
\operatorname{sgn}^{+}(x)= \begin{cases}1, & \text { if } x>0 \\ 0, & \text { if } x \leq 0\end{cases}
$$




\subsection{Problem Context}

In this problem, a DISCO owns and operates the distribution system and provides an electricity service to all its customers. However, the DISCO does not own candidate DG but manages its connection to the system. This section describes the DISCO's financial benefits when evaluating potential IPP and SG connections, and proposes an optimal planning model to help the DISCO to determine what locations and capacities to promote as owners of IPP and SG seek access to the network. A central authority specifies DG eligibility criteria and a quota for RESs for a set period, which in this paper is one year.

The financial benefit for IPP lies in income from energy production, while SG benefits from cost savings due to the reduction of energy consumption and income from energy production. Although the implementation and extent of compensation vary widely and depends on commercial arrangements, the overall structure takes the form of net metering or payments for energy produced and energy exported. In this paper, the DISCO incurs the cost of surplus energy that is exported to the distribution network.

The framework for the location and capacity planning problem is illustrated in Fig. 1. The DISCO receives a mandate to integrate a certain amount of RES from a central authority. It can exercise several options to meet the quota requirement. The options are: accept full financial penalties and not connect renewable DG, combine DG connections and penalty payments, or fill quota through DG integration. Other inputs consist of price and cost parameters, and representative load and DG resource data. The objective is to maximize profit and in the process, ensure generation and network constraints are satisfied. The outputs of the model are the locations and capacities of IPP and SG. The next section provides a mathematical formulation of the proposed model. 


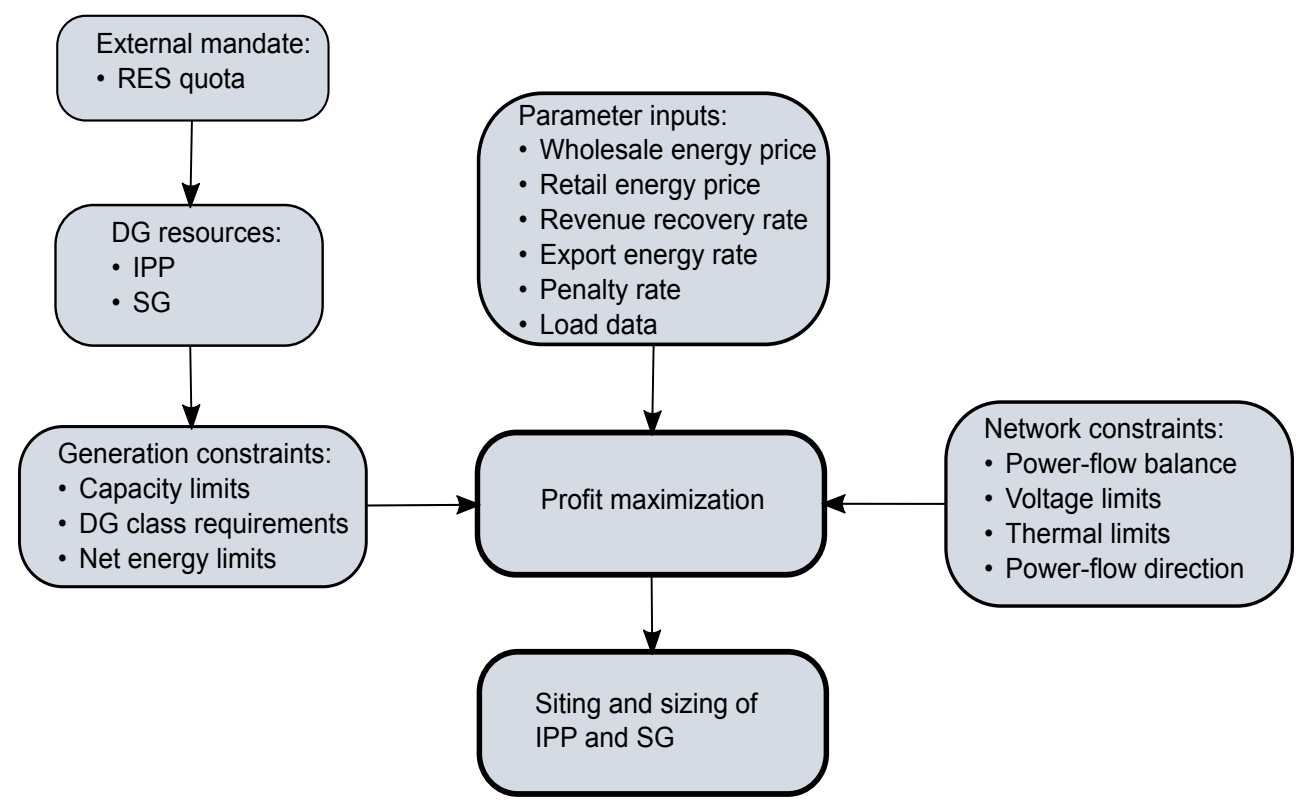

Fig. 1. Proposed framework for DG location and capacity planning

\subsection{Mathematical Formulation}

The objective of the DISCO is to maximize profit, defined in (2) as the revenue from the sale of energy minus the cost of energy and quota compliance.

$$
\max J_{P}=J_{D}-J_{Q},
$$

where $J_{D}$ is the gross profit from the sale of energy and incentives for revenue loss and SG energy export and $J_{Q}$ is the penalty payment for renewable energy shortfall. $J_{D}$ is defined as

$$
J_{D}=\mu_{a}+\mu_{b}-\mu_{c}+\mu_{d}-\mu_{e} .
$$

Without SG, $J_{D}$ is simply the revenue from energy sales less the cost of wholesale energy $\left(\mu_{a}-\mu_{c}\right)$. Components $\mu_{b}, \mu_{d}$ and $\mu_{b}$ are introduced by the integration of SG with on-site energy use. Fig. 2 shows how each one captures the temporal interaction between on-site generation and load. The formulation of the different components is described in more detail in (44)-(10). 


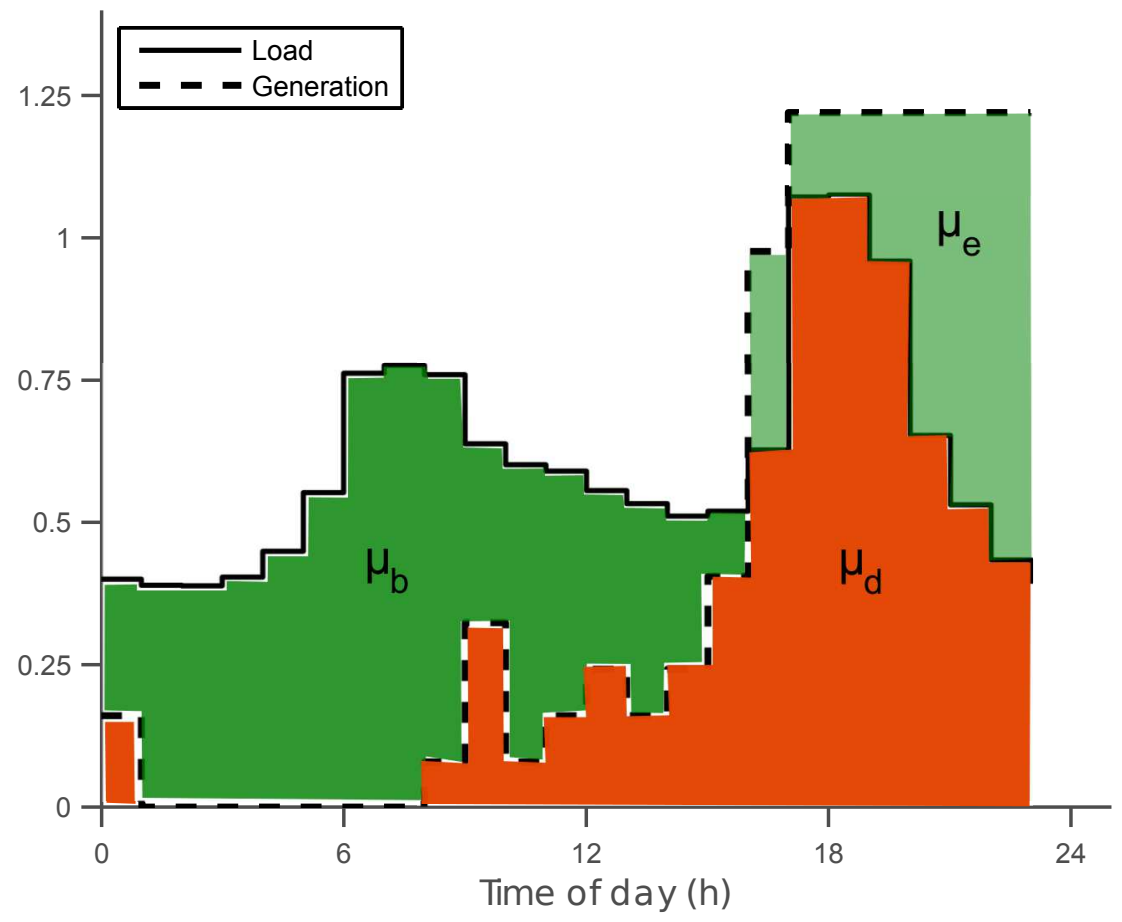

Fig. 2. Representation of SG impact through regions between load and generation curves

a) Energy Retail $\left(\mu_{a}\right)$. This is revenue from selling energy to consumers on the network, expressed as:

$$
\mu_{a}=C^{\mathrm{r}} \sum_{t \in T} \sum_{d \in D} P_{\mathrm{L}, d}^{t} \tau
$$

b) Revenue Erosion $\left(\mu_{b}\right)$. This term represents reduced revenue due to lower energy consumption at candidate SG locations (Fig. 2). The loss of revenue caused by SG is proportional to the local generation level. Of course, when local generation is zero at any SG site, true demand is revealed and the DISCO receives full income as is the case with pure load buses. To obtain $\mu_{b}$ we require the power difference between local load and generation at $\mathrm{SG}$ locations, $P_{k, t}^{\mathrm{E}}$, which is given by (5).

$$
P_{k, t}^{\mathrm{E}}=P_{\mathrm{SGL}, k}^{t}-P_{\mathrm{SG}, k}^{t} .
$$

The above difference is translated into an energy import or export status, denoted 
by the notation $u_{k, t}^{\mathrm{e}}$, and expressed by the sign of $P_{k, t}^{\mathrm{E}}$ as follows:

$$
u_{k, t}^{\mathrm{e}}:=\operatorname{sgn}^{+}\left(P_{k, t}^{\mathrm{E}}\right) .
$$

Using (5) and (66) we finally obtain $\mu_{b}$ in (7) as

$$
\mu_{b}=C^{\mathrm{r}} \sum_{t \in T} \sum_{k \in K} P_{k, t}^{\mathrm{E}} \tau u_{k, t}^{\mathrm{e}} .
$$

c) Wholesale Energy Cost $\left(\mu_{c}\right)$. The DISCO purchases energy at the wholesale price, $C^{e}$ from the substation and IPP to supply all loads not supplied by SG. This term represents the total wholesale energy cost and is given by (8) .

$$
\mu_{c}=C^{\mathrm{e}} \sum_{t \in T}\left(P_{\mathrm{s}}^{t}+\sum_{i \in I} P_{\mathrm{IPP}, i}^{t}\right) \tau .
$$

d) Revenue Recovery $\left(\mu_{d}\right)$. This term represents a revenue recovery mechanism, which is the proportion of the total revenue recovered after introducing SG to the system (Fig. 2). The costs are recovered from ratepayers or through other means available to the DISCO for dealing with revenue erosion. The expression for revenue recovery is written as:

$$
\mu_{d}=C^{\mathrm{rv}} \sum_{t \in T} \sum_{k \in K}\left(P_{\mathrm{SG}, k}^{t} u_{k, t}^{\mathrm{e}}+P_{\mathrm{SGL}, k}^{t}\left(1-u_{k, t}^{\mathrm{e}}\right)\right) \tau .
$$

e) Energy Export Cost $\left(\mu_{e}\right)$. This term is the value the DISCO places on energy exported by SG (Fig. 2). The resulting cost represents the DISCO's partial contribution to FiTs and is therefore not recovered from ratepayers.

$$
\mu_{e}=C^{\mathrm{ee}} \sum_{t \in T} \sum_{k \in K} P_{k, t}^{\mathrm{E}} \tau\left(u_{k, t}^{\mathrm{e}}-1\right) .
$$

From (10), the unit cost of exported energy can differ from that in (8), depending on the value of $C^{\mathrm{ee}}$. For instance, if $C^{\mathrm{ee}}=0$ a saving in wholesale energy cost is realized, once the SG capacity rises to levels whereby generation exceeds demand. 
In contrast, $C^{\mathrm{ee}}=C^{\mathrm{e}}$ means the unit rates of energy from SG, IPP and upstream sources are all identical.

The full mathematical expression for $J_{D}$, written in (11), is composed of (44)-(10).

$$
\begin{aligned}
J_{D}=\underbrace{C^{\mathrm{r}} \sum_{t \in T} \sum_{d \in D} P_{\mathrm{L}, d}^{t} \tau}_{\mu_{a}} & +\underbrace{C^{\mathrm{r}} \sum_{t \in T} \sum_{k \in K} P_{k, t}^{\mathrm{E}} \tau u_{k, t}^{\mathrm{e}}}_{\mu_{b}}-\underbrace{C^{\mathrm{e}} \sum_{t \in T}\left(P_{\mathrm{s}}^{t}+\sum_{i \in I} P_{\mathrm{IPP}, i}^{t}\right) \tau}_{\mu_{c}} \\
& +\underbrace{C^{\mathrm{rv}} \sum_{t \in T} \sum_{k \in K} P_{\mathrm{SG}, k}^{t} \tau u_{k, t}^{\mathrm{e}}}_{\mu_{d}}-\underbrace{C^{\mathrm{ee}} \sum_{t \in T} \sum_{k \in K} P_{k, t}^{\mathrm{E}} \tau\left(u_{k, t}^{\mathrm{e}}-1\right)}_{\mu_{e}} .
\end{aligned}
$$

The penalty payment, $J_{Q}$, defined in (12), is required when total IPP capacity is lower than predefined quota, which is given as a percentage of the total energy delivered to consumers.

$$
J_{Q}=\left(C^{\mathrm{b}} \sum_{t \in T}\left(r^{\mathrm{o}}\left(\sum_{d \in D} P_{\mathrm{L}, d}^{t}-\sum_{k \in K} P_{\mathrm{SG}, k}^{t}\right)-\sum_{i \in I} P_{\mathrm{IPP}, i}^{t}\right) \tau\right) u_{\mathrm{c}}
$$

where the notation $u_{\mathrm{c}}$ indicates whether or not the DISCO complies with the quota obligation, and is defined by the sign function $\operatorname{sgn}^{+}$as:

$$
u_{\mathrm{c}}=\operatorname{sgn}^{+}\left(\sum_{t \in T}\left(r^{\mathrm{o}}\left(\sum_{d \in D} P_{\mathrm{L}, d}^{t}-\sum_{k \in K} P_{\mathrm{SG}, k}^{t}\right)-\sum_{i \in I} P_{\mathrm{IPP}, i}^{t}\right) \tau\right) \text {. }
$$

Of note, SG reduces the quota by decreasing the total energy on which the quota is based.

The objective function $\left(J_{P}=J_{D}-J_{Q}\right)$ is maximized subject to the constraints (14)(21), which are described below.

1) $S G$ Net Energy Limits. The total energy produced by SG is expressed in relation to local energy use over the evaluation period, permitting net consumers and net exporters. Local energy production from SG is therefore limited according to the given maximum allowable generation percentage $a_{L}$ using (14).

$$
\sum_{t \in T} \sum_{k \in K} P_{\mathrm{SG}, k}^{t} \leq a_{L} \sum_{t \in T} \sum_{k \in K} P_{\mathrm{SGL}, k}^{t} .
$$


2) Power-flow Constraints. The total power consumption must be equal to the total power supply at each bus, maintaining power-flow balance over the th interval according to (15) and (16).

$$
\begin{aligned}
P_{\mathrm{G}, d}^{t}-P_{\mathrm{L}, d}^{t}= & V_{d}^{t} \sum_{j=1}^{D} V_{j}^{t}\left[G_{d j}^{t} \cos \left(\delta_{d}^{t}-\delta_{j}^{t}\right)\right. \\
& \left.+B_{d j}^{t} \sin \left(\delta_{d}^{t}-\delta_{j}^{t}\right)\right], \\
Q_{\mathrm{G}, d}^{t}-Q_{\mathrm{L}, d}^{t}= & V_{d}^{t} \sum_{j=1}^{D} V_{j}^{t}\left[G_{d j}^{t} \sin \left(\delta_{d}^{t}-\delta_{j}^{t}\right)\right. \\
& \left.-B_{d j}^{t} \cos \left(\delta_{d}^{t}-\delta_{j}^{t}\right)\right] .
\end{aligned}
$$

3) Voltage Limits. The voltage at each bus must be maintained within the appropriate range, defined by (17), at all times.

$$
V^{\min } \leq V_{d}^{t} \leq V^{\max }
$$

4) Capacity Restrictions. SG capacity must be in the permitted range, according to (18).

$$
0 \leq G_{\mathrm{SG}, k} \leq G_{\mathrm{SG}, k}^{\max }
$$

The IPP capacity constraint stems from a differentiating rule for SG and IPP. For an IPP connection to be allowed, its capacity must be higher than the upper limit for an SG. Therefore no single DG unit can be categorized as both an SG and an IPP. The requirement is considered by limiting IPP capacity using (19),

$$
G_{\mathrm{IPP}, i}^{\min } \leq G_{\mathrm{IPP}, i} \leq G_{\mathrm{IPP}, i}^{\max }
$$

for $G_{\mathrm{IPP}, i}>0$. 
5) Thermal Limits. Thermal loading of lines and transformers must be less than the levels derived from manufacture ratings and safety regulations as in (20).

$$
\left(P_{d, j}^{t^{2}}+Q_{d, j}^{t^{2}}\right)^{1 / 2} \leq S_{d, j}^{\max } .
$$

6) Reverse Power-flow Restriction. The power flow at the distribution substation must not be negative, meaning the distribution system must not export power upstream as in (21).

$$
P_{\mathrm{s}}^{t} \geq 0 .
$$

In summary, the location and capacity planning optimisation problem incorporating SG and IPP is formulated by maximizing profit, defined by (2), subject to constraints, (14) $-(21)$.

\section{Case Studies}

The proposed optimisation model is applied to the 33- and 69-bus systems shown in Fig. 3 and 4, and the solutions are found by Matlab. Although the model is applicable to any generator categorized as SG or IPP, wind energy is the technology selected for all DG in the system for ease of illustration. Candidate buses for SG and IPP connections on the 33-bus system are 6,13 and 28. The 69-bus system comprises potential connections at buses 7, 11, 21, 35, 45 and 61 . SG-6 and SG-61 represent SG located at bus 6 and bus 61 . The same convention is followed for IPP. The voltage variations at each bus of the distribution systems are expected to be within the range $\pm 5 \%$. Detailed information of the 33-bus system can be found in [27] and that of the 69-bus system in [28]. The 33-bus system is henceforth identified as Case A and the 69-bus system, Case B. The maximum capacity for a single SG must be lower than 3 MW, which is the minimum value for an IPP. Table 1 contains values of parameters which serve as inputs to the base-case simulation. Several other scenarios are created 


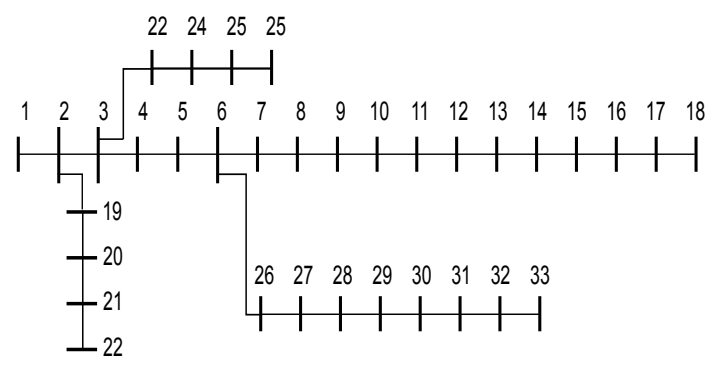

Fig. 3. The 33-bus distribution system schematic diagram

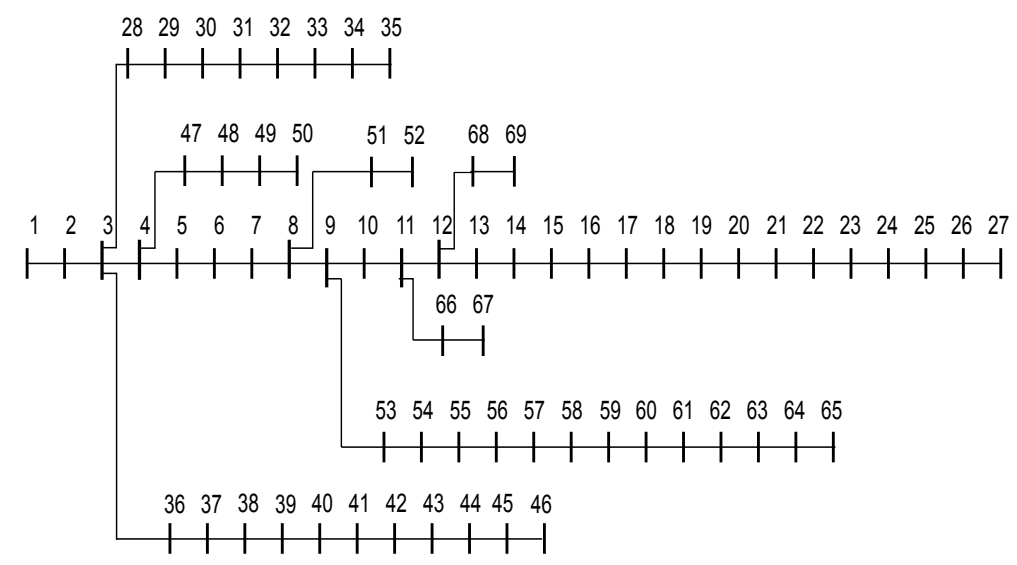

Fig. 4. The 69-bus distribution system in schematic form

mainly to quantify the performance of the proposed model in the event of parameter changes.

\section{Results and Discussion}

This section demonstrates the benefits of the proposed model, compares it to other approaches and ascertains its sensitivity to quota, net energy limit, incentives - these are revenue recovery and cost of exported energy - and minimum capacity variations.

\subsection{Result Comparisons}

Here, we benchmark the base-case simulation results of the proposed DG location and capacity optimisation model against those of other methods using parameter data from Table 1. The proposed model is compared with hybrid approaches consisting of a combination of optimisation and rule-based models. For the hybrid approaches, DG 
Table 1

Parameter values for the base-case simulation

\begin{tabular}{ll}
\hline Wholesale price of electricity $\left(C^{\mathrm{e}}\right)$ & $50 £ / \mathrm{MWh}$ \\
Retail price of electricity $\left(C^{\mathrm{r}}\right)$ & $75 £ / \mathrm{MWh}$ \\
Penalty rate for non-compliance $\left(C^{\mathrm{b}}\right)$ & $20 £ / \mathrm{MWh}$ \\
Revenue recovery rate $\left(C^{\mathrm{rv}}\right)$ & $0.5 C^{\mathrm{r}} £ / \mathrm{MWh}$ \\
DISCO energy export rate $\left(C^{\mathrm{ee}}\right)$ & $0.5 C^{\mathrm{e}} £ / \mathrm{MWh}$ \\
SG net energy limit $\left(a_{L}\right)$ & $120 \%$ \\
IPP quota $\left(r^{\mathrm{o}}\right)$ & $23 \%$ \\
Minimum IPP capacity $\left(G_{\mathrm{IPP}, i}^{\mathrm{min}}\right)$ & $3 \mathrm{MW}$ \\
\hline
\end{tabular}

location and capacity are determined with a well-established method, which finds the maximum capacity to satisfy voltage and thermal constraints as in [29]. Because the method presents no DG segmentation, SG and IPP capacity shares are consequently apportioned according to predefined rules. For Approach A, DG is not deployed on the network. Approaches B - D correspond to the hybrid approaches composed of the method presented in [29] supplemented with defined rules for DG segmentation. Approach E employs the proposed DG location and capacity optimisation model. The description of the approaches considered is given below.

Approach A (No DG): System remains free of DG in the presence of quota obligation. Approach B (IPP only): Find locations that maximize DG capacity. Allocate all of the capacity to IPP.

Approach C (SG only): Find locations that maximize DG capacity. Allocate all of the capacity to SG.

Approach D (Limited $S G$ ): Find locations that maximize DG capacity, limit SG integration to $5 \%$ of load and allocate the remaining capacity to IPP. This approach reflects current practice in some jurisdictions such as California [30].

Approach E: Apply proposed optimisation model to determine a combination of SG and IPP at different locations, which maximizes profit. 
Table 2 presents a summary of the results of the various approaches for DG location and capacity planning. Evidently, Approaches B - D produce low profits, constraint violations and inconsistent performance. The main reason for the constraint violations is that only one location yields maximum DG capacity in all these approaches. That is, bus 6 in Case A and bus 61 in Case B. In contrast, the proposed model (Approach E) maximizes profit with respect to all the stated constraints, (14) - (21), without any violations. In Case A, only Approach A, B and E produce feasible results. Approach C offers the highest profit but the concentration of SG at a single location (bus 6) results in a violation of the limit for SG net energy. It is apparent that Approach E satisfies all constraints and carries increased profit simultaneously. Compared to the system without SG and IPP, the profit is raised by $23.7 \%$ to $£ 1.692 \mathrm{~m}$. Similar results are found in Case B, where another constraint - the minimum IPP capacity limit - is violated. The reason for the violation is that there is insufficient network capacity (1.221 MW) to satisfy the minimum requirement for IPP capacity (3 MW). Notably, for this case the highest infeasible profit belongs to Approach B. It is thus observed that none of Approaches B - D is unable to satisfy all constraints and maximize profit in both Case A and B. These results highlight discrepancies that can be expected when there is no inherent representation of SG and IPP within DG planning models. It is apparent that Approach $\mathrm{E}$ is the only one that provides feasible profit maximisation.

If the SG net energy and minimum IPP capacity limits are not binding, the results of Approaches B - D will become feasible. Tables 3 and 4 show the comparison of all the approaches when these constraints are removed. The results also include lack of recovery of lost revenue $\left(C^{\mathrm{rv}}=0\right)$ following network integration of SG in both the partially and fully constrained scenarios. As expected, Approach E has the highest profit in the partially constrained scenarios for Cases A and B. It is also, yet again, the only feasible approach to provide the highest profits in the fully constrained scenario. Furthermore, it improves the result of Approach $\mathrm{C}$ in Case $\mathrm{B}$ by $8 \%$. The corresponding profit breakdown of the two approaches is plotted in Fig. 5. It can be seen that Approach E suffers less revenue erosion, with lower energy export cost. This is due to the fact that 
Approach E allocates SG capacity to more locations than Approach C (Table 4).

Table 2

Comparison of location and capacity allocation approaches

\begin{tabular}{|l|l|l|l|l|}
\hline & \multicolumn{2}{|c|}{ Case A } & \multicolumn{2}{c|}{ Case B } \\
\hline Approach & $J_{P}\left(£ \times 10^{3}\right)$ & Violated const. & $J_{P}\left(£ \times 10^{3}\right)$ & Violated const. \\
\hline A & 1367.996 & None & 332.047 & None \\
\hline B & 1676.466 & None & 406.920 & min. IPP capacity \\
\hline C & 1839.303 & SG net energy & 350.856 & None \\
\hline D & 1698.830 & SG net energy & 392.527 & min. IPP capacity \\
\hline E & 1692.445 & None & 352.129 & None \\
\hline
\end{tabular}

\subsection{Sensitivity Analyses}

In this section, the results of the proposed optimisation model in the presence of parameter changes are analysed.

\subsubsection{Quota}

The values of $r^{\circ}$ are systematically changed from $10 \%$ to $35 \%$. All other parameters maintain the values in Table 1.

Case A: Fig. 6 shows the share of each DG category in Case A. The financial implications of the quota adjustments can be seen in Fig. (7) Quotas between 0 and 20\% are easily met without filling up network capacity, hence the penetration of SG at all candidate locations is limited by the local net energy limits. Over the same quota range, the profit remains unchanged because the penalty payment for non-compliance is not imposed. It is suggested that the potential loss of revenue due to SG connection coupled with revenue recovery and energy export benefits do not maximize profit at a quota of $25 \%(4.921 \mathrm{MW})$. Despite the fact that maximum network capacity is $5.148 \mathrm{MW}$, 
Table 3

Comparison of location and capacity allocation approaches $\left(C^{\mathrm{rv}}=0\right)$

\begin{tabular}{|c|c|c|c|c|}
\hline \multicolumn{5}{|c|}{ Partially constrained (excl. minimum IPP capacity and SG net energy limits) } \\
\hline & \multicolumn{4}{|c|}{ Case A } \\
\hline Approach & \multicolumn{2}{|r|}{$J_{P}\left(£ \times 10^{3}\right)$} & SG MW (Bus) & IPP MW (Bus) \\
\hline $\mathrm{A}$ & \multicolumn{2}{|r|}{1367.996} & 1367.996 & 0 \\
\hline $\mathrm{B}$ & \multicolumn{2}{|r|}{1676.466} & 0 & $5.1481(6)$ \\
\hline $\mathrm{C}$ & \multicolumn{2}{|r|}{1823.355} & $5.1481(6)$ & 0 \\
\hline $\mathrm{D}$ & \multicolumn{2}{|r|}{1685.659} & $0.7268(6)$ & $4.4212(6)$ \\
\hline $\mathrm{E}$ & \multicolumn{2}{|r|}{1823.355} & $5.1481(6)$ & 0 \\
\hline \multicolumn{5}{|c|}{ Fully constrained } \\
\hline & \multicolumn{4}{|c|}{ Case A } \\
\hline Approach & $J_{P}\left(£ \times 10^{3}\right)$ & SG MW (Bus) & IPP MW (Bus) & Violated const. \\
\hline $\mathrm{A}$ & 1367.996 & 0 & 0 & None \\
\hline $\mathrm{B}$ & 1676.466 & 0 & $5.1481(6)$ & None \\
\hline $\mathrm{C}$ & - & $5.1481(6)$ & 0 & SG net energy \\
\hline $\mathrm{D}$ & - & $0.7268(6)$ & $4.4212(6)$ & SG net energy \\
\hline $\mathrm{E}$ & 1678.045 & $0.0905(13), 0.6032(28)$ & $4.3679(6)$ & None \\
\hline
\end{tabular}


Table 4

Comparison of location and capacity allocation approaches $\left(C^{\mathrm{rv}}=0\right)$

\begin{tabular}{|c|c|c|c|c|}
\hline \multicolumn{5}{|c|}{ Partially constrained (excl. minimum IPP capacity and SG net energy limits) } \\
\hline & \multicolumn{4}{|c|}{ Case B } \\
\hline Approach & \multicolumn{2}{|c|}{$J_{P}\left(£ \times 10^{3}\right)$} & SG MW (Bus) & IPP MW \\
\hline A & \multicolumn{2}{|c|}{332.047} & 0 & 0 \\
\hline $\mathrm{B}$ & \multicolumn{2}{|c|}{406.920} & 0 & $1.221(61)$ \\
\hline $\mathrm{C}$ & \multicolumn{2}{|c|}{316.085} & 1.221 & 0 \\
\hline $\mathrm{D}$ & \multicolumn{2}{|c|}{382.344} & $0.239(61)$ & $0.982(61)$ \\
\hline $\mathrm{E}$ & \multicolumn{2}{|c|}{442.450} & $0.4842(7), 0.7365(45)$ & 0 \\
\hline \multicolumn{5}{|c|}{ Fully constrained } \\
\hline & \multicolumn{4}{|c|}{ Case B } \\
\hline Approach & $J_{P}\left(£ \times 10^{3}\right)$ & SG MW (Bus) & IPP MW (Bus) & Violated const. \\
\hline $\mathrm{A}$ & 332.047 & 0 & 0 & None \\
\hline $\mathrm{B}$ & - & 0 & $1.221(61)$ & min. IPP capacity \\
\hline $\mathrm{C}$ & 316.085 & $1.221(61)$ & 0 & None \\
\hline $\mathrm{D}$ & - & $0.2389(61)$ & $0.9821(61)$ & min. IPP capacity \\
\hline $\mathrm{E}$ & 341.359 & $\begin{array}{l}0.0609(7) \\
0.2186(11) \\
0.1719(21) \\
0.0090(35) \\
0.0591(45)\end{array}$ & 0 & None \\
\hline
\end{tabular}




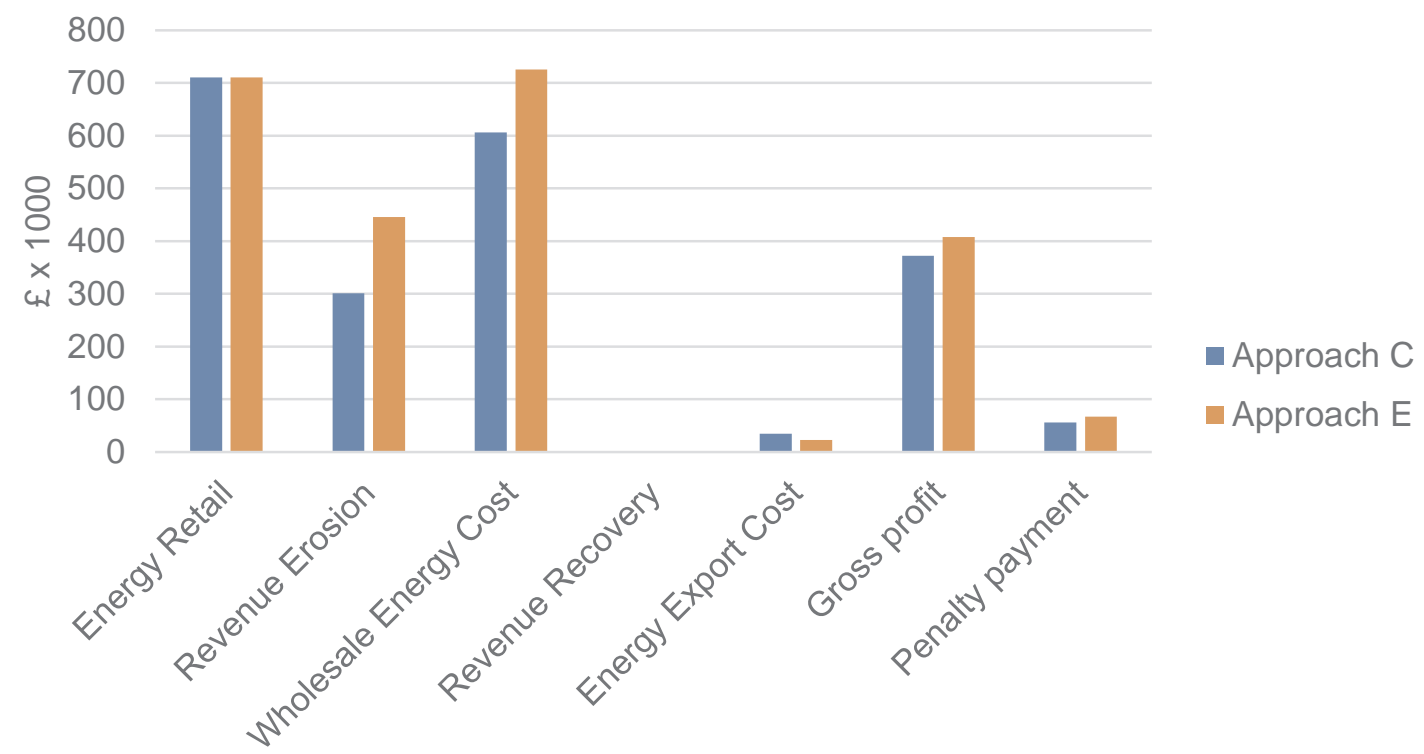

Fig. 5. Breakdown of DISCO profit

with $0.227 \mathrm{MW}$ (5.148 MW - 4.921 MW) is unused, there is a clear lack of SG (Fig. 6). As a result recovered revenue and cost of exported energy fall to zero. Eventually, beyond the $25 \%$ quota, IPP integration reaches maximum network capacity - $35 \%$ quota equals 6.89 MW, which is higher than the maximum available capacity of 5.148 MW. The increasing deficit also increases the penalty payment and therefore reduces profit. The reason for the lack of IPP capacity at bus 13 and bus 28 can be traced back to the IPP capacity restriction in (19). IPP is connected only if it meets the minimum capacity requirement of $3 \mathrm{MW}$ or higher. Allocating capacity to IPP at three different locations uses up at least $9 \mathrm{MW}$ of capacity, which is significantly higher than the maximum network capacity.

Case B: The allocation of network location and capacity using the proposed model manifests two clear patterns in Case B, which represent repeated allocations as the quota is varied. These patterns are labelled Variation $\mathrm{A}$ and $\mathrm{B}$ and are shown in Fig. 8. Through Variation A the model distributes capacity among multiple buses, and through Variation B, it assigns all network capacity to a single bus. The highest available network capacity is $1.221 \mathrm{MW}$ regardless of parameter changes. Since the minimum capacity limit for IPP is $3 \mathrm{MW}$, it is again not possible to connect IPP. 


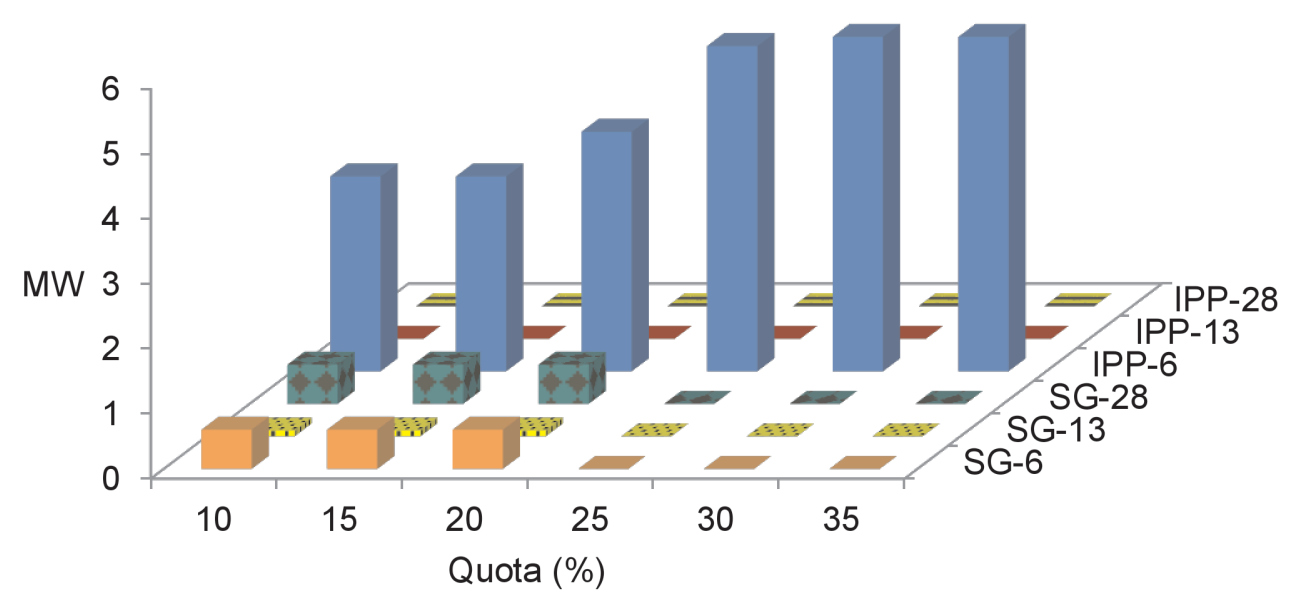

Fig. 6. DG location and capacity for Case A under quota adjustments

Therefore $100 \%$ of available capacity is allocated to SG. Variation A is produced for quotas below 30\%. Variation B, which provides additional 0.52 MW over variation A, is selected for quota requirements in excess of $30 \%$. Profit from the sale of energy and incentives, $J_{D}$, is calculated as $£ 418,861$ for Variation A and $£ 406,595$ for Variation B. However, Variation B suffers less penalties $\left(J_{Q}\right)$ because of higher capacity. The penalty payment generally increases with rising quota, as seen in Fig. 7 . It is found that Variation A causes relatively small differences $\left(J_{P}\right)$ between $J_{D}$ and $J_{Q}$ at quotas of $25 \%$ and below but higher differences for quotas above $25 \%$ compared to Variation B. For example, at the quota of $15 \%, J_{P}$ for variation B is $£ 370,243$. As seen in Fig. 7, $J_{P}$ for Variation A is clearly higher at $£ 375,340$. For a quota of $30 \%$, Variation A produces $£ 331,816$ for $J_{P}$ whereas Variation B yields $£ 333,891$, which is the value displayed in Fig. 7. This is how the model allocates capacity - by selecting Variation A for quotas below 25\%, and Variation B for quotas above $25 \%$.

\subsubsection{Net Energy Limit}

The SG net energy limit supply is altered in steps of $20 \%$ from $60 \%$ to $200 \%$ of local demand. Limits below 100\% imply that SG units are not allowed to generate more energy than they consume while higher limits permit supply in excess of local consumption. 

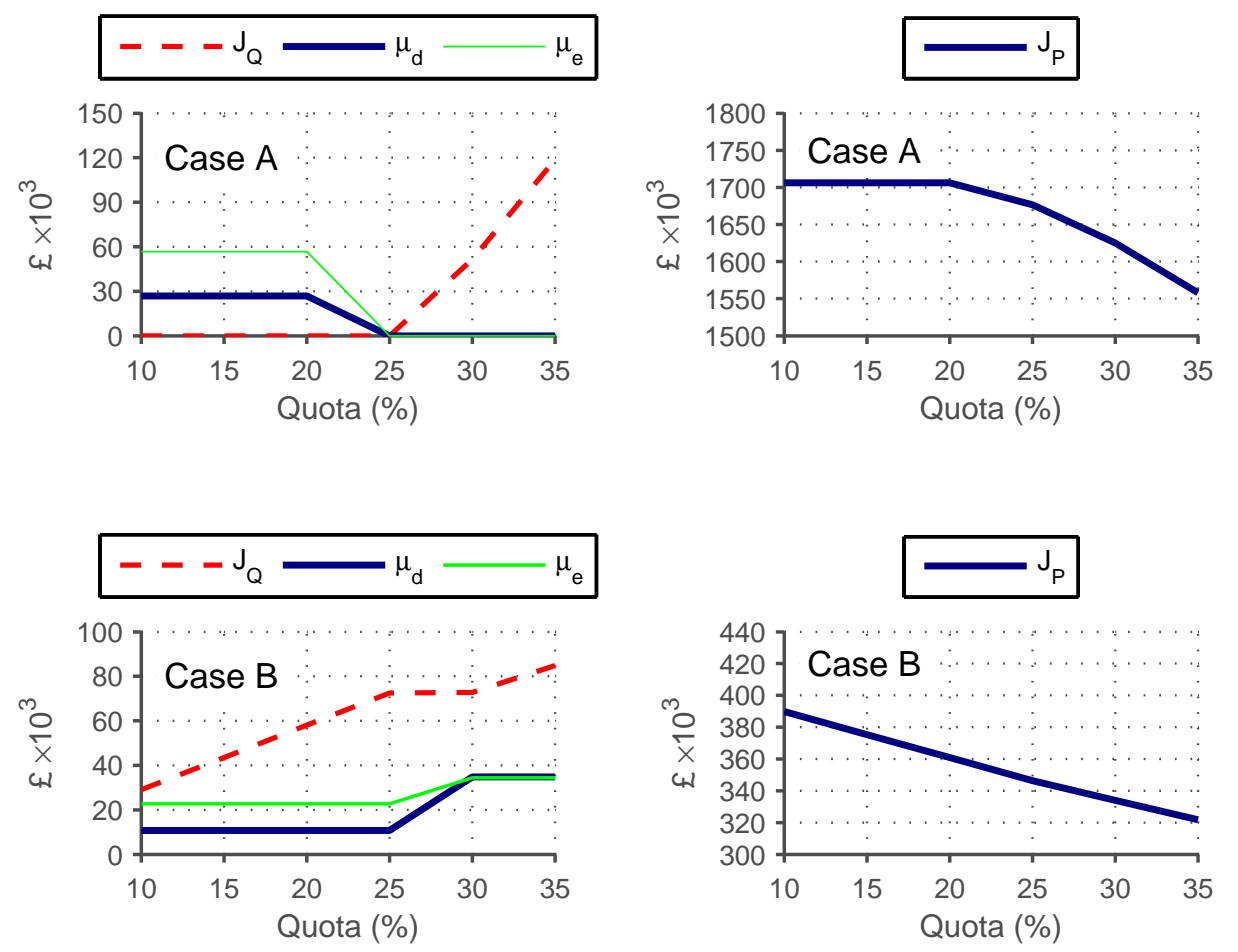

Fig. 7. Cost and revenue variations due to quota adjustments
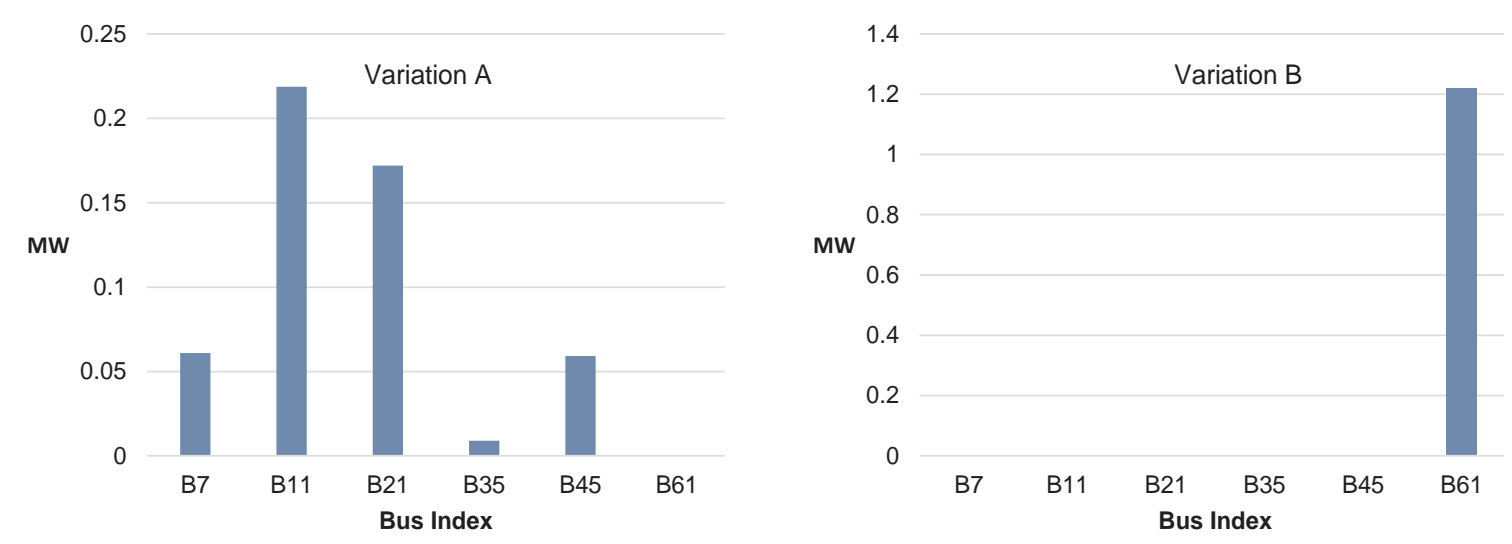

Fig. 8. SG location and capacity patterns for Case B 
Case A: The impacts of the SG net energy limit on capacity and financial flows are shown in Fig. 9 and Fig. 10, In general, restricting SG energy output to levels below local consumption is not as profitable for the DISCO as allowing net energy export, assuming other parameters in Table 1 remain unchanged. Net energy limits around $60 \%$ and below render SG unprofitable, hence network capacity is solely allocated to IPP (Fig. 9). Some capacity remains in these situations because the fixed quota of $23 \%$ is less than available network capacity. However, the additional capacity is allocated to IPP since there is no upper cap for the quota mechanism. As a result there is a high level of compliance when it comes to the quota obligation mechanism. When the SG net energy limit is relaxed, more capacity is allocated to SG and the DISCO profit increases in return (Fig. 10). However, SG is deployed at bus 6 but displaced at other buses when the limit reaches $140 \%$ (Fig. 9). The explanation for this change is that SG at one location can export more energy to the network at a cost of $0.5 C^{\mathrm{e}}$ without a significant further reduction of revenue from energy sales. Once the net energy limit exceeds 160\%, SG begins displacing IPP, causing activation of the penalty charge for quota non-compliance (Fig. 9 and 10).

Case B: Financial results for Case B are shown in Fig. 10, with the corresponding capacity details presented in Fig. 11. The connection of IPP is ruled out by the minimum limit of 3 MW (Table1), so all network capacity is allocated to SG. Consequently, raising the net energy limit has an immediate effect of decreasing the penalty payment for quota non-compliance (Fig. 10). Sharing of capacity between all candidate locations is varied to produce an almost linearly rising profit as the net energy limit is increased.

\subsubsection{Revenue Recovery and Energy Export Rate}

Fig. 12 and 13 show variations of financial performance in response to changing recovery and DISCO export rates for Case A and Case B. $J_{Q 1}, J_{Q 2}$ and $J_{Q 3}$ represent penalty payments corresponding to export rates of $C^{\mathrm{ee}}, 0.5 C^{\mathrm{ee}}$ and 0 , respectively. The same export rates apply for numbered subscripts relating to $J_{P}, \mu_{d}$ and $\mu_{e}$. 


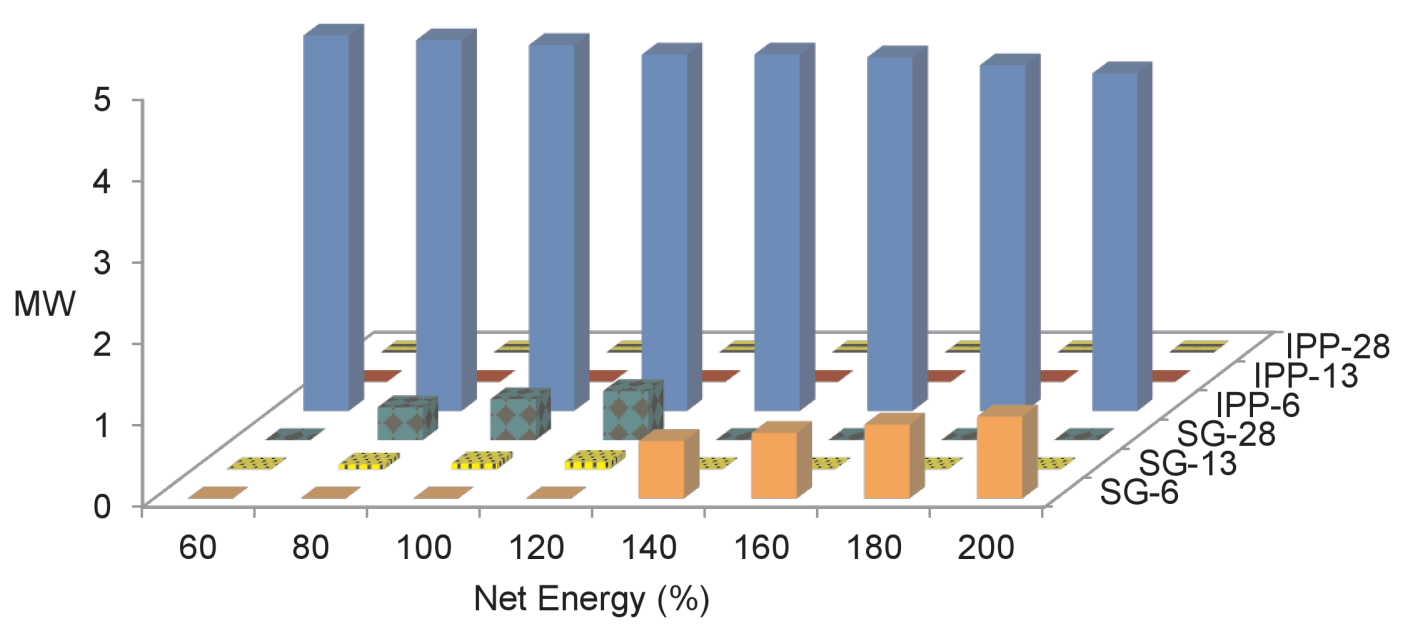

Fig. 9. Capacity allocation for Case A under net energy restrictions
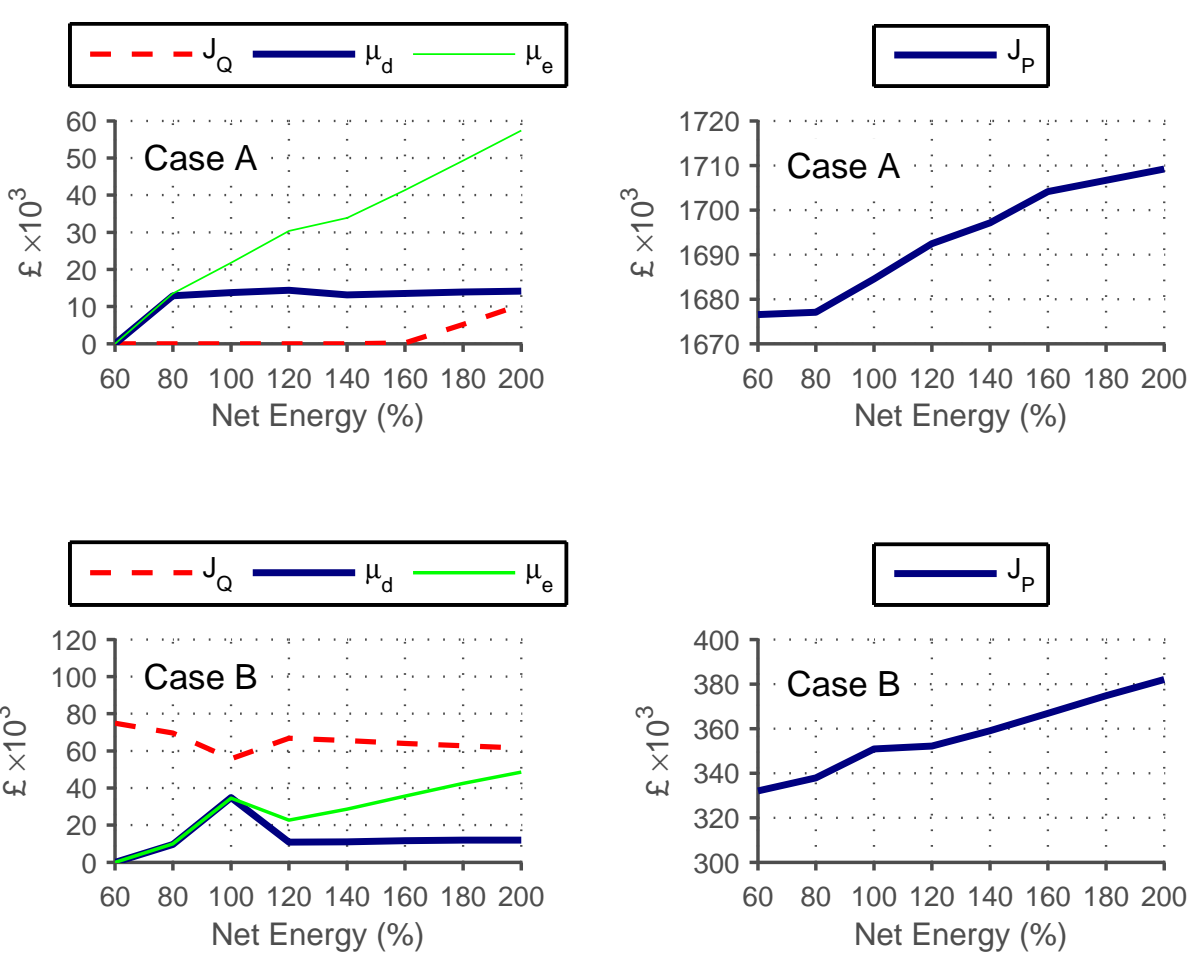

Fig. 10. Cost and revenue variations due to net energy limit adjustments 


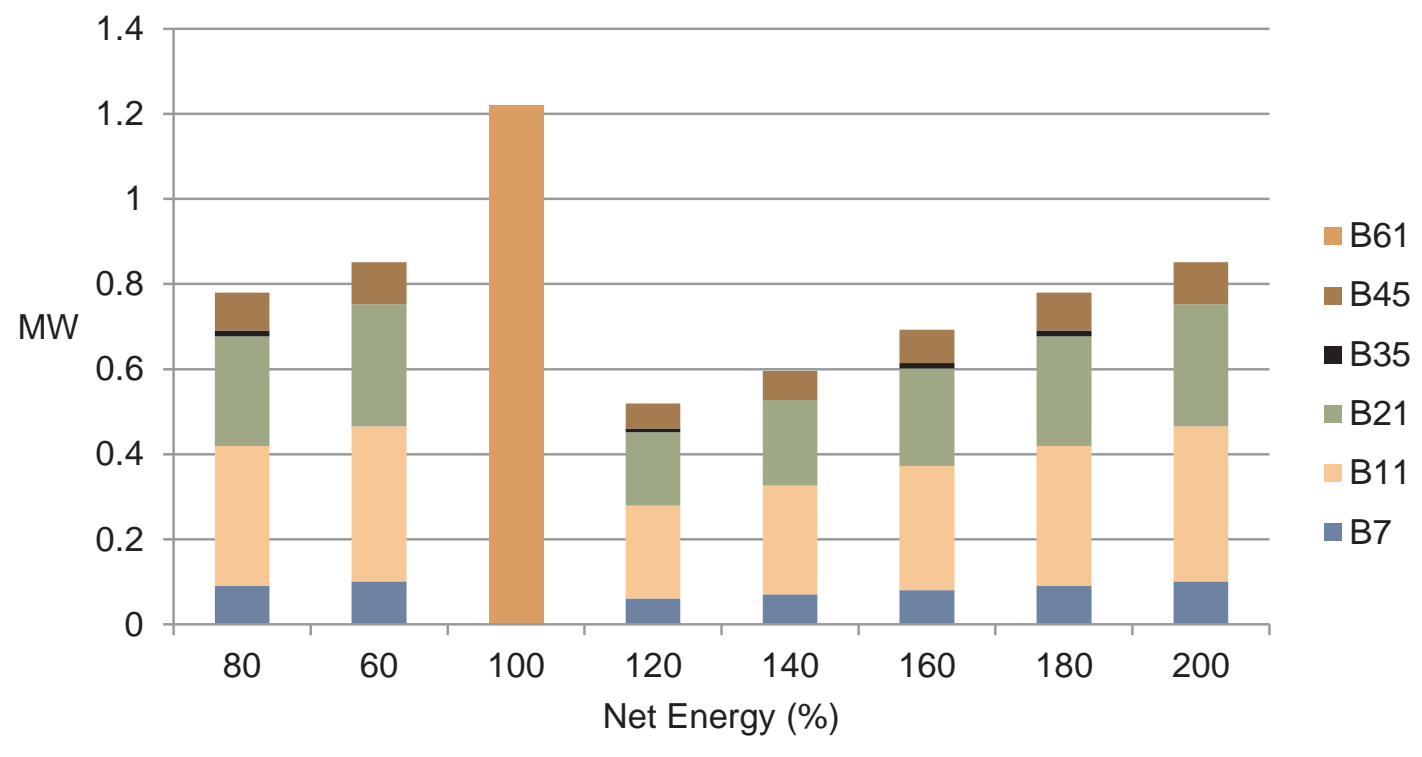

Fig. 11. Capacity allocation for Case B under net energy restrictions

Case A: Based on Fig. 12, the DISCO remains compliant and incurs no financial penalty at the export rates of $C^{\mathrm{ee}}$ and $0.5 C^{\mathrm{ee}}$. When the export rate is 0 , the penalty payment increases to $£ 31,251$. In general, profit rises proportionally with the revenue recovery rate unless the export rate is equal to the retail price. In this case the profit is constant for all values of $C^{\text {rv }}$ from zero up to $C^{\mathrm{e}}$.

Case B: The DISCO is unable to avoid the penalty payment regardless of revenue recovery and export rates adjustments because the maximum network capacity is less than the prescribed IPP capacity (Fig [13). The highest penalty values are observed at the revenue recovery rates below $C^{\mathrm{e}}$. In contrast, the total revenue recovery and energy export payment increase as the revenue recovery rate rise to $0.5 \mathrm{C}^{\mathrm{e}}$ and above. As in Case $\mathrm{A}$, the highest profit is encountered when the revenue recovery rate equals the wholesale price and the export rate is zero.

\subsubsection{Minimum IPP Capacity Limit}

The adjustments of the minimum capacity restriction for IPP are realized by modifying $G_{\mathrm{IPP}, i}^{\min }$ in (19). This constraint affects how much DG capacity is allocated to IPP and SG, as shown in Table 5 for both Cases A and B. 

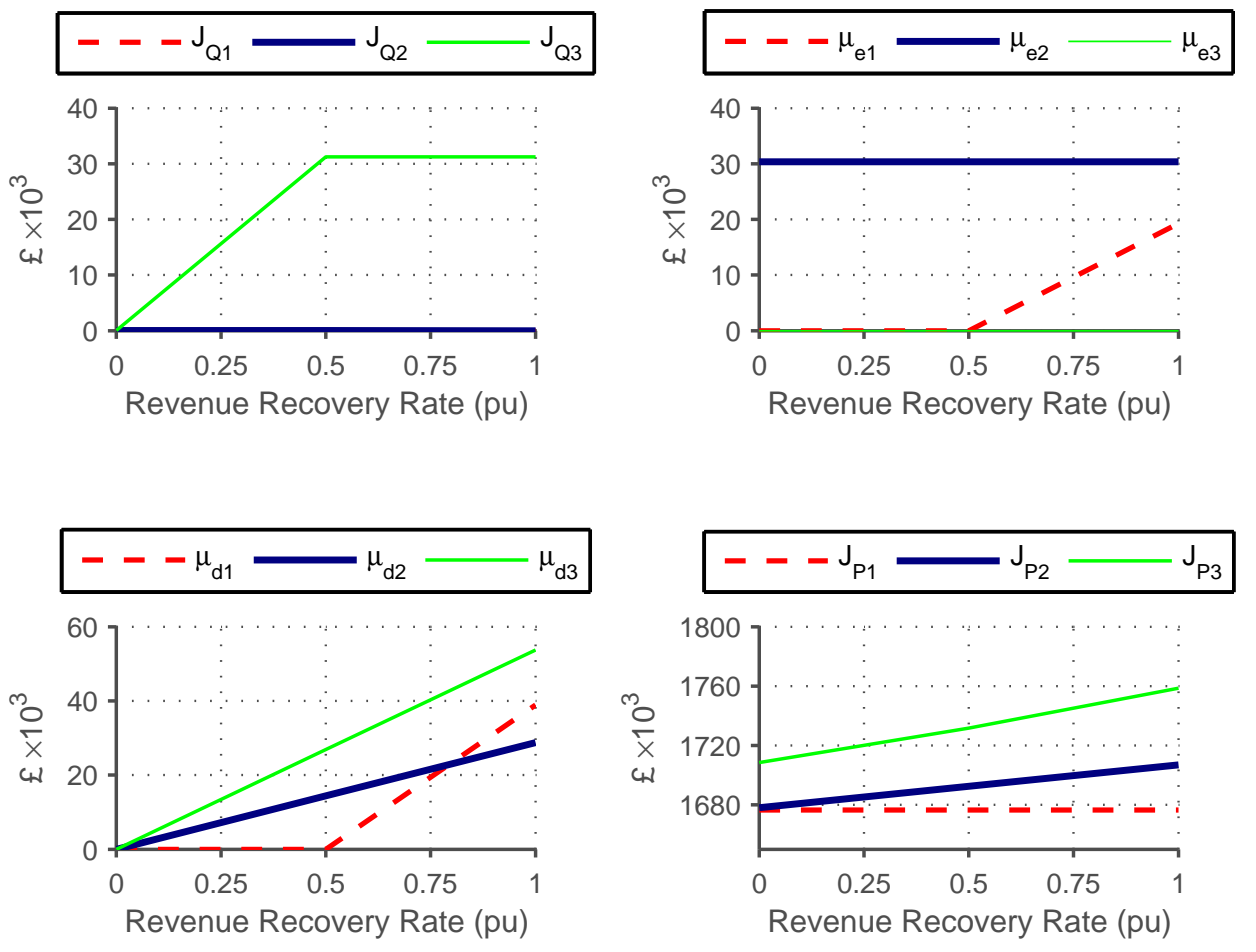

Fig. 12. Cost and revenue variations under revenue recovery and energy export rate adjustments for Case A 

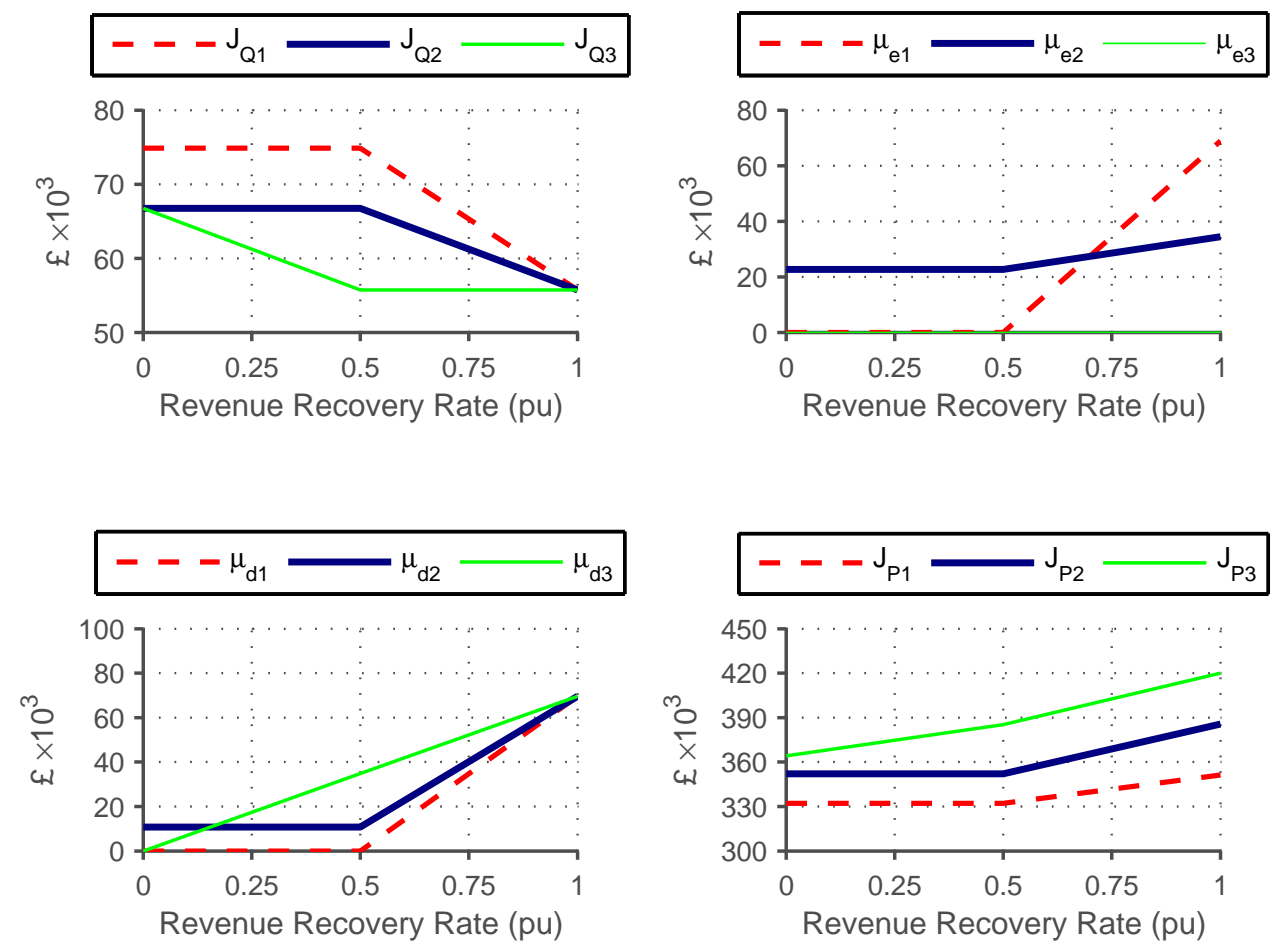

Fig. 13. Cost and revenue variations under revenue recovery and energy export rate adjustments for Case B 
Table 5

Impact of restricting IPP capacity

\begin{tabular}{|l|l|l|l|}
\hline \multicolumn{5}{|c|}{ Case A } \\
\hline IPP limit $(\mathrm{MW})$ & $J_{P}\left(£ \times 10^{3}\right)$ & SG $(\mathrm{MW})$ & IPP $(\mathrm{MW})$ \\
\hline$\geq 4$ & 1692.445 & 0.6937 & 4.37 \\
\hline$\geq 5$ & 1676.466 & 0 & 5 \\
\hline$\geq 6$ & 1418.1 & 1.2969 & 0 \\
\hline \multicolumn{4}{|c|}{ Case B } \\
\hline IPP limit $(\mathrm{MW})$ & $J_{P}\left(£ \times 10^{3}\right)$ & $\mathrm{SG}(\mathrm{MW})$ & IPP $(\mathrm{MW})$ \\
\hline$\geq 1$ & 408.63 & 0.22 & 1 \\
\hline$\geq 1.22$ & 406.92 & 0 & 1.22 \\
\hline$\geq 2$ & 352.129 & 1.068 & 0 \\
\hline
\end{tabular}


Case A: Any value of $G_{\mathrm{IPP}, i}$ that exceeds the quota specification removes the financial penalty for the DISCO as long as system constraints are satisfied. Given the network constraints (17), (20) and (21), raising the lower limit to $6 \mathrm{MW}$ makes IPP connections. This is because the maximum DG capacity on the network is $5.148 \mathrm{MW}$. At all candidate locations, maximum SG capacity is reached, amounting to a total of 1.297 MW (Table 5). In other words, the binding constraint for SG is the net energy limit. As a result, it is observed that raising the net energy limit will result in more use of network capacity by SG in the absence of IPP.

Case B: As seen in Table 5, IPP connection is only made possible by much lower capacity restrictions. An apparent issue in the preceding analyses is that, Case B has insufficient capacity for IPP at $3 \mathrm{MW}$ and above. However, it does opens up to IPP at limits of $1 \mathrm{MW}$ and below. In fact, the observation is that, to ensure that capacity is allocated to both IPP and SG in the two cases, the minimum limit must be set at 1.22 MW or lower. Therefore relaxation of the minimum capacity cap encourages better diffusion of network capacity.

\subsection{Application to Renewable Energy Programmes}

The utility of the proposed model can be viewed from the perspectives of the DISCO and the regulator. For the DISCO, the model provides the capability to guide decisions of investors by releasing information and incentives for connection opportunities that increase or preserve profits. As discussed, the DISCO can maximize profit given varying regulatory conditions. However, revenue recovery and discounted export cost will lead to increased prices for ratepayers. Therefore, the results of the model must also carry relevance for regulation. Consequently, the profit of the DISCO must not be too low to discourage DG integration, nor be excessively high, which can lead to a substantial increase in profits at the ratepayers' expense.

There are other ways in which the model can be used in this context. During the design of renewable energy programmes, the model can assist in deciding the limits of minimum IPP capacity and SG net energy. The minimum limit for IPP can have 
the effect of displacing either IPP or SG. If the limit is too high, IPP investors will be subjected to high costs of connection and delays due to the requirements for network reinforcement or access higher voltage levels. A high net energy limit can lead to concentration of SG at few locations. This means that only few DISCO customers will be able to obtain network access, further undermining the roll-out of RESs.

\section{Conclusion}

In this paper, an optimal DG location and capacity planning model is proposed in which DG is separated into IPP and SG in accordance with the requirements of practical policy schemes such as quota obligation and FiT. The unique capability of the proposed optimisation model is that the DISCO will be able to integrate IPP and SG into distribution networks without relying on predefined rules. In particular, it is shown that the DISCO gains the capability to conduct location and capacity evaluations for these DG categories, in support of profit maximization. The obligation to meet renewable energy quota and the import-export impact of SG are embedded within the model. This ensures the most favourable financial position for the DISCO, considering the trade-off between penalty payment and RES connection. Furthermore, financial aspects specific to SG connection - revenue erosion, recovery and energy export cost are considered to complete the objective function. Unlike standard models with predefined rules for IPP and SG deployment, the model presented in this paper is able to satisfy constraints unique to each DG category while maximising profit. Notably, the standard models violate SG net energy and IPP capacity limits because the import and export capability of SG as well as the lower bound of IPP capacity are not taken into account. In contrast, the proposed model enables facilitation of IPP and SG connections while raising profits by up to $23.7 \%$ without violating any constraints. It is also demonstrated using the obtained model, that changes in renewable energy quota, net energy limit and other parameters cause variations in location and distribution of capacity between IPP and SG as profit is maximized. 


\section{References}

[1] IRENA, Renewable Energy Target Setting (2015).

[2] A. Piccolo, P. Siano, Evaluating the impact of network investment deferral on distributed generation expansion, IEEE Trans. Power Syst. 24 (3) (2009) 1559-1567.

[3] M. F. Shaaban, Y. M. Atwa, E. F. El-Saadany, DG allocation for benefit maximizationin distribution networks, IEEE Trans. Power Syst. 28 (2) (2013) 639-649.

[4] T. Niknam, S. I. Taheri, J. Aghaei, S. Tabatabaei, M. Nayeripour, A modified honey bee mating optimization algorithm for multiobjective placement of renewable energy resources, Applied Energy 88 (2011) 4817-4830.

[5] M. A. Abdullah, A. P. Agalgaonkar, K. M. Muttaqi, Assessment of energy supply and continuity of service in distribution network with renewable distributed generation, Applied Energy 113 (2014) 1015-1026.

[6] D. Q. Hung, N. Mithulananthan, R. C. Bansal, An optimal investment planning framework for multiple distributed generation units in industrial distribution systems, Applied Energy 124 (2014) 62-72.

[7] G. P. Harrison, A. Piccolo, A. R. Wallace, Exploring the tradeoffs between incentives for distributed generation developers and DNOs, IEEE Trans. Power Syst. 22 (2) (2007) $821-828$.

[8] G. Harrison, A. Piccolo, P. Siano, A. R. Wallace, Hybrid ga and opf evaluation of network capacity for distributed generation connections, Elect. Power Syst. Res. 78 (3) (2008) 392-398.

[9] H. A. Hejazi, A. R. Araghi, B. Vahidi, S. H. Hosseinian, M. Abedi, H. Mohsenian-Rad, Independent distributed generation planning to profit both utility and DG investor, IEEE Trans. Power Syst. 28 (2) (2013) 1170-1178.

[10] W. El-Khattam, K. Bhattacharya, Y. Hegazy, M. M. A. Salama, Optimal investment planning for distributed generation in a competitive electricity market, IEEE Trans. Power Syst. 19 (3) (2004) 1674-1684. 
[11] K. M. Muttaqi, A. D. T. Le, J. Aghaei, E. Mahboubi-Moghaddam, M. Negnevitsky, G. Ledwich, Optimizing distributed generation parameters through economic feasibility assessment, Applied Energy 165 (2016) 893-903.

[12] D. Gautam, N. Mithulananthan, Optimal DG placement in deregulated electricity market, Elect. Power Syst. Res. 77 (12) (2007) 1627-1636.

[13] J. M. López-Lezama, J. Contreras, A. Padilha-Feltrin, Location and contract pricing of distributed generation using a genetic algorithm, Int. J. Electr. Power Energy Syst. 36 (1) (2012) 117-126.

[14] I. Das, K. Bhattacharya, C. Cañizares, Optimal incentive design for targeted penetration of renewable energy sources, IEEE Trans. Sustain. Energy 5 (4) (2014) 1213-1225.

[15] California Public Utilities Code, Distributed Energy Resources, Available: http://goo.gl/vjAU8N

[16] BC Hydro, About independent power projects, Available: https://goo.gl/JQWZgM.

[17] H. Park, R. Baldick, Stochastic generation capacity expansion planning reducing greenhouse gas emissions, IEEE Trans. Power Syst. 30 (2) (2015) 1026-1034.

[18] F. Careri, C. Genesi, P. Marannino, M. Montagna, S. Rossi, I. Siviero, Generation expansion planning in the age of green economy, IEEE Trans. Power Syst. 26 (4) (2011) $2214-2223$.

[19] S. Wong, K. Bhattacharya, D. Fuller, Long-term effects of feed-in tariffs and carbon taxes on distribution systems, IEEE Trans. Power Syst. 25 (3) (2010) 1241-1253.

[20] S. Abolhosseini, A. Heshmati, The main support mechanisms to finance renewable energy development, Renew. Sustain. Energy. Rev. 40 (2014) 876-885.

[21] P. Menanteau, D. Finon, M.-L. Lamy, Prices versus quantities: choosing policies for promoting the development of renewable energy, Energy Policy 31 (2003) 799-812. 
[22] N. Aparicio, I. MacGill, J. R. Abbad, H. Beltran, Comparison of wind energy support policy and electricity market design in Europe, the United States, and Australia, IEEE Trans. Sustain. Energy 3 (3) (2012) 809-818.

[23] E. McKenna, M. Thomson, Photovoltaic metering configurations, feed-in tariffs and the variable effective electricity prices that result, IET Renew. Power. Gener. 7 (3) (2013) $235-245$.

[24] S. H. Oliva, I. MacGill, R. Passey, Assessing the short-term revenue impacts of residential PV systems on electricity customers, retailers and network service providers, Renew. Sustain. Energy. Rev. 54 (2016) 1494-1505.

[25] E. Hirst, C. Goldman, Key issues in integrated resource planning for electric utilities, IEEE Trans. Power Syst. 5 (4) (1990) 1105-1253.

[26] A. Satchwell, A. Mills, G. Barbose, Regulatory and ratemaking approaches to mitigate financial impacts of net-metered PV on utilities and ratepayers, Energy Policy 85 (2015) $115-125$.

[27] B. E. Baran, F. F. Wu, Network reconfiguration in distribution systems for loss reduction and load balancing, IEEE Trans. Power Del. 4 (2) (1989) 1401-1407.

[28] B. E. Baran, F. F. Wu, Optimal capacitor placement on radial distribution systems, IEEE Trans. Power Del. 4 (1) (1989) 725-734.

[29] G. N. Koutroumpezis, A. S. Safigianni, Optimum allocation of the maximum possible distributed generation penetration in a distribution network, Elect. Power Syst. Res. 80 (12) (2010) 1421-1427.

[30] J. Heeter, R. Gelman, L. Bird, Status of Net Metering: Assessing the Potential to Reach Program Caps, National Renewable Energy Laboratory (NREL) (2010). 